\title{
Ambulatory Esophageal pH Monitoring: New Directions
}

\author{
Ram Dickman Ronnie Fass \\ The Neuro-Enteric Clinical Research Group, Department of Medicine, Section of Gastroenterology, \\ Southern Arizona VA Health Care System and the Section of Nutrition, Arizona Cancer Center, \\ University of Arizona Health Sciences Center, Tucson, Ariz., USA
}

\begin{abstract}
Key Words
Ambulatory esophageal $\mathrm{pH}$ monitoring $\cdot$ Wireless esophageal $\mathrm{pH}$ monitoring $\cdot \mathrm{Bravo}^{\mathrm{TM}}$ wireless $\mathrm{pH}$ capsule $\cdot$ Multichannel intraluminal impedance $\cdot$ Acid reflux assessment $\cdot$ Bilitec monitoring system • SmartPill ACT-1 capsule
\end{abstract}

\begin{abstract}
$\mathrm{pH}$ testing remains a commonly used evaluative tool in clinical practice. However, the original tool that included a nasally placed $\mathrm{pH}$ catheter was plagued with a variety of shortcomings, primarily the effect of the procedure on patients' lifestyle and thus on reflux-provoking activities. The miniaturization of evaluative techniques in gastroenterology was the impetus for the development of the wireless $\mathrm{pH}$ capsule and the SmartPill. These modalities improve patients' tolerability of the required test and provide a unique opportunity for expansion of indications and data collection. The introduction of the multichannel intraluminal impedance with a $\mathrm{pH}$ sensor allowed the detection of gastroesophageal reflux that is non-acidic. However, the value of the technique beyond the realm of academic gastroenterology remains to be elucidated. Recently, there was a renewal of interest in Bilitec 2000. The technique, which has never found a clear clinical role, has been recommended as an impor-
\end{abstract}

tant tool in evaluating patients who failed proton pump inhibitor therapy. However, data to support its clinical value in this situation have remained scant.

Copyright $(2006$ S. Karger AG, Basel

\section{Introduction}

Ambulatory 24-hour esophageal $\mathrm{pH}$ monitoring is commonly used in clinical practice and has been considered in the past as the 'gold standard' for the diagnosis of gastroesophageal reflux disease (GERD) [1-4]. The current indications for esophageal $\mathrm{pH}$ testing include continuation of classic GERD symptoms while on doubledose proton pump inhibitor (PPI) therapy (PPI failure), evaluation prior to antireflux surgery of patients with non-erosive reflux disease (NERD), recurrence of GERDrelated symptoms after antireflux surgery and continuation of atypical/extraesophageal manifestations of GERD despite an empirical therapy with a PPI [1-7].

Ambulatory 24-hour esophageal $\mathrm{pH}$ monitoring provides continuous recording of the $\mathrm{pH}$ in the esophagus. The probe is traditionally positioned $5 \mathrm{~cm}$ above the proximal margin of the lower esophageal sphincter (LES). The relatively high location in the esophagus was promoted in the hope to avoid migration of the $\mathrm{pH}$ probe into the stomach or the repeated sampling of the stomach

\section{KARGER}

Fax +41613061234 E-Mail karger@karger.ch www.karger.com 


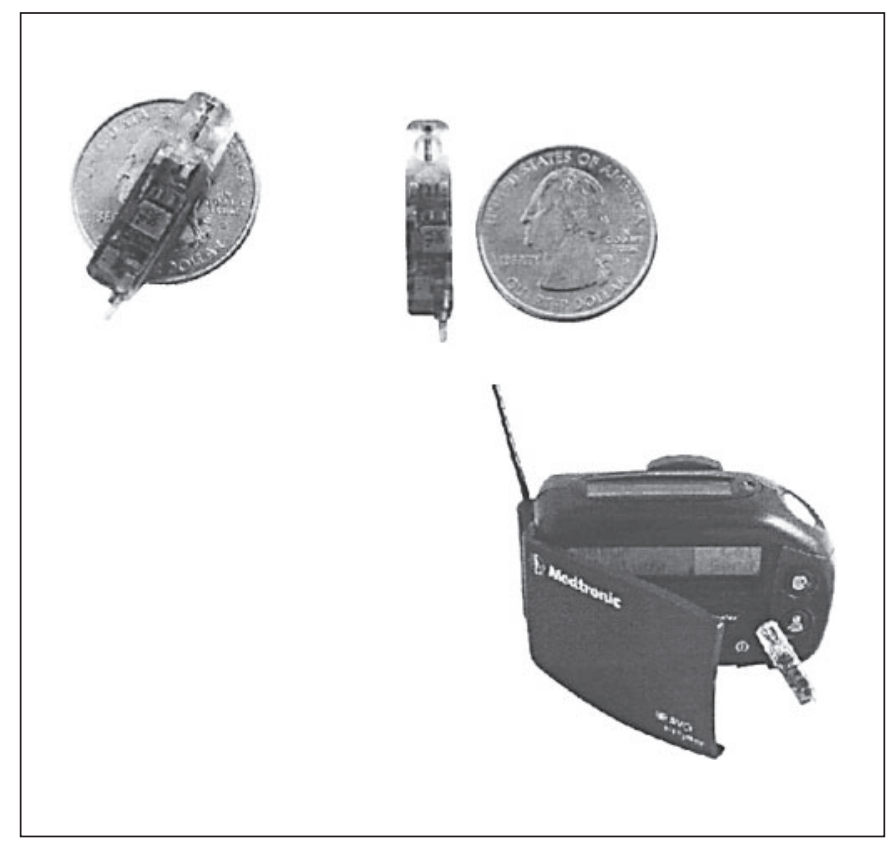

Fig. 1. $\mathrm{Bravo}^{\mathrm{TM}} \mathrm{pH}$ monitoring system (capsule and receiver).

content during swallowing and consequently esophageal shortening. Additionally, changes in body position, swallowing or phonation may induce rolling or bending of the probe resulting in proximal displacement or even inadvertent migration of the probe into the stomach, leading to erroneous results $[8,9]$.

The sensitivity of the $\mathrm{pH}$ test has been limited by the day-to-day variability in esophageal acid exposure. Furthermore, the impact of the test per se on reflux provoking activities, the presence of non-acidic reflux (bile, pancreatic enzymes) which the test does not detect and inherent limitations of the $\mathrm{pH}$ sensor itself, have all resulted in reduced sensitivity. This may explain the high percentage of false negative $\mathrm{pH}$ tests in patients with erosive esophagitis (up to 25\%) and even higher in subjects with NERD $[8,9]$. Disadvantages of the transnasal placement of the $\mathrm{pH}$ probe include social embarrassment, limitation of normal activities, reduction in food consumption, interruption of normal sleep and untoward complications such as dysphagia, nasal pain and throat discomfort. The latter may lead to poor tolerance of the procedure by patients undergoing 24-hour esophageal $\mathrm{pH}$ monitoring. Additionally, the occurrence of gastroesophageal reflux events and symptoms might be affected leading to false negative results $[6,10,11]$. The various shortcomings of the catheter-based technique served as the impetus for the development of the wireless $\mathrm{pH}$ system.

\section{Wireless Esophageal pH Monitoring}

The Bravo ${ }^{\mathrm{TM}}$ wireless $\mathrm{pH}$ capsule (Medtronic Inc., Shoreview, Minn., USA) is a recently developed $\mathrm{pH}$ monitoring system which avoids the need for an indwelling transnasal probe by utilizing a capsule that can be attached to the esophageal mucosa either orally or transnasally (fig. 1). The Bravo $\mathrm{pH}$ system consists of a capsule attached to the end of a catheter delivery system and a pager-size receiver. The capsule $(6 \times 5.5 \times 25 \mathrm{~mm})$ has an antimony $\mathrm{pH}$ and reference electrodes located within the distal end which also contains a battery and a transmitter. The capsule has a well $(4 \times 3.5 \mathrm{~mm})$ which is connected to a vacuum pump via the delivery system. When the vacuum is applied ( $>500 \mathrm{~mm} \mathrm{Hg}$ ), esophageal mucosa is drawn into the well and is subsequently secured by a stainless pin. The latter is launched by an activation button. Thereafter, by twisting clockwise $\left(90^{\circ}\right)$ and extending the activation button, the delivery system is released from the capsule. The capsule transmits $\mathrm{pH}$ data, using radiotelemetry, to a portable receiver, which is worn on the patient's belt.

\section{Techniques of Placement and Patient Instructions}

If the $\mathrm{pH}$ capsule is delivered after an upper endoscopy then the proper location of placement is $6 \mathrm{~cm}$ above the esophagogastric junction. A standard esophageal manometry is needed to identify the proximal margin of the LES if placement of the capsule is performed without prior endoscopy. In this case the capsule can be delivered transnasally or perorally [11].

Recording of $\mathrm{pH}$ data is commonly carried out over a period of $48 \mathrm{~h}$. Patients are instructed to keep a diary and record meal times, position changes, and the time and type of their symptoms. Patients are encouraged to pursue their everyday activities and usual diet. Reflux is defined as $\mathrm{pH}<4$ and reflux time as the interval until $\mathrm{pH}>4$. Data analysis is performed using standard, commercially available computer software (Medtronic Inc.). Presently, the receiver has two recording channels, allowing placement of up to 2 capsules simultaneously. The maximum range of the receiver is $3-5 \mathrm{ft}$, allowing patients to shower or go to sleep with the receiver placed close by. 


\section{Data from Studies}

Two studies have assessed the performance, tolerability and safety of the wireless $\mathrm{pH}$ system after an endoscopic placement $[12,13]$. Both studies concluded that the wireless $\mathrm{pH}$ capsule is well tolerated and a reliable tool for quantifying esophageal acid exposure. In both studies, placement of the wireless $\mathrm{pH}$ capsule was performed immediately after an upper endoscopy, which may not be an option for many open access motility laboratories at referral centers. In contrast, Wong et al. [8] compared the performance, feasibility and tolerability of transnasal/ peroral placement of the wireless $\mathrm{pH}$ capsule versus the traditional $\mathrm{pH}$ probe (Slimline catheter with Mark III Digitrapper, Medtronic Inc.). The study compared reported daily activity, food consumption, habits, symptoms, sleep, adverse events, quality of life and overall perceived experience of both groups. The authors demonstrated that the recorded $\%$ total, supine or upright time $\mathrm{pH}<4$ was similar by both techniques. Additionally, patients who underwent placement of the wireless $\mathrm{pH}$ capsule reported less nose pain, runny nose, throat pain, throat discomfort and headache as compared with those who received the traditional $\mathrm{pH}$ probe. In contrast, patients in the wireless $\mathrm{pH}$ capsule group reported more chest discomfort. Overall, patients in the wireless $\mathrm{pH}$ capsule group perceived the test as less interfering with their daily activities, food consumption or sleep and reported a higher satisfaction rate [8].

The wireless $\mathrm{pH}$ system offers extended recording capabilities as compared with the $\mathrm{pH}$ catheter-based technique [11-13]. Currently, studies are conducted over a period of $48 \mathrm{~h}$ but potentially may be extended to even longer periods of time. Studies have demonstrated that by increasing the $\mathrm{pH}$ recording time, from 24 to $48 \mathrm{~h}$, the yield of the procedure increased in capturing more abnormal $\mathrm{pH}$ tests or symptom-associated reflux events [14]. Prakash and Clouse [14] found that by extending the recording time to $48 \mathrm{~h}$ with the wireless $\mathrm{pH}$ monitoring system, the number of subjects recording symptoms during the test increased by $6.8 \%$, but the number of symptoms available for association with acid reflux events was doubled. The study also showed that patients with atypical GERD symptoms benefited the most from extending the duration of the $\mathrm{pH}$ study. Furthermore, in patients who were off antireflux therapy, extended recording time increased the proportion of subjects with abnormal esophageal acid exposure time by $12.4 \%$ and significantly increased the likelihood of finding a positive relationship between symptoms and acid reflux events [14].

Esophageal pH Monitoring
Whilst the wireless $\mathrm{pH}$ capsule is expected to detach from the esophageal wall within 7 days after placement, in a few anecdotal reports the capsule remained attached for a longer period of time, requiring endoscopic removal [15]. Occasionally, patients may request to have the capsule removed shortly after placement, primarily due to chest discomfort. The latter complaint appeared to be more common in patients with functional esophageal disorders like functional heartburn or non-cardiac chest pain. The chest discomfort is commonly exacerbated during meals due to pulling of the capsule when the food bolus is propelled through the esophagus.

In summary, the Bravo wireless $\mathrm{pH}$ monitoring system is safe, well tolerated and a reliable method for measuring esophageal acid exposure. The procedure is better tolerated than the traditional catheter-based technique. Extending $\mathrm{pH}$ recording time to 2 days appears to increase the sensitivity of the test. The wireless $\mathrm{pH}$ capsule represents a breakthrough in the GI motility field that will likely be followed by miniaturization of other methods to assess GI function and sensation. Whilst cost still limits the general usage of the wireless $\mathrm{pH}$ capsule, the simplicity of its placement and the potential for increase in reimbursement are likely to make the technique popular even among community-based gastroenterologists.

\section{Multichannel Intraluminal Impedance and pH Sensor}

Multichannel intraluminal impedance (MII) is a new technique that evaluates esophageal function as well as bolus characteristics [16]. By combining the MII with a pH sensor (MII-pH, Sandhill Scientific, Denver, Colo., USA) the technique can determine the $\mathrm{pH}$ of a refluxate. Additionally, the proximal extent of a refluxate can also be determined. Thus, the MII-pH system provides for the first time information about the presence of a refluxate that is either acidic or weakly acidic $(4<\mathrm{pH}<7)$. Studies have suggested that the MII-pH system may be useful in evaluating weakly acidic reflux in patients with persistent typical or atypical symptoms of GERD despite treatment with acid suppression [16-18].

\section{Acid Reflux Assessment}

The MII-pH system consists of a 2.1-mm polyvinyl catheter that includes six pairs of cylinder-shaped metallic electrodes (each $4 \mathrm{~mm}$ in length, set at 2-cm intervals) 
and one antimony $\mathrm{pH}$ sensor. The impedance catheter is swallowed and positioned within the esophageal body ensuring that the $\mathrm{pH}$ sensor is located $5 \mathrm{~cm}$ above the proximal margin of the LES.

Studies using simultaneous measurements of intraesophageal impedance and $\mathrm{pH}$ demonstrated that the rate of gastroesophageal reflux (liquid, gas or mixture of gas and liquid, acidic or weakly acidic) was similar in patients with GERD and normal controls [17]. However, more acidic reflux (45 vs. 33\%) was noted in the GERD group. Vela et al. [18] observed that treatment of GERD patients with omeprazole twice daily resulted in postprandial reflux that was predominately weakly acidic as compared to baseline (prior to PPI treatment). Classic GERD symptoms were more common with acid reflux but were also induced by weakly acidic reflux [18]. In contrast, regurgitation appeared to be associated more with weakly acidic reflux. Regardless, it has yet to be determined if the content or volume are responsible for classic GERD symptoms in the studied subjects. Furthermore, it is unclear if the shift to weakly acidic reflux during PPI treatment leads to persistence of GERD symptoms or just represents the effect of PPIs in general on reflux characteristics. A better design of the study would have been the comparison of reflux characteristics between patients who failed PPI therapy and those that demonstrated complete symptom resolution. Sifrim et al. [19] assessed the role of ambulatory esophageal impedance and $\mathrm{pH}$ measurements in 22 patients with chronic unexplained cough. The study evaluated the temporal association between cough and gastroesophageal reflux (acid, weakly acidic and weakly alkaline) and clearly identified a subgroup of patients with chronic cough associated with weakly acidic gastroesophageal reflux [19].

The sensitivity of impedance to detect gastroesophageal reflux was compared with that of pH-metry and/or esophageal manometry. As compared to $\mathrm{pH}$ testing, impedance detected $97-98 \%$ of acid reflux events [20]. Impedance also detected $95 \%$ of all reflux events diagnosed by combined manometry and $\mathrm{pH}$ testing [21]. Data from other studies indicated that impedance has a sensitivity of at least $90 \%$ for detecting all reflux episodes [22].

In summary, it seems that the impedance probe with an integrated $\mathrm{pH}$ sensor may potentially become an important tool for assessment of refluxate composition and its relationship to symptoms [17-18].

\section{The Bilitec Monitoring System}

Bilitec is a fiberoptic spectrophotometer (Bilitec 2000; Medtronic Inc.) that detects bilirubin in an ambulatory setting. The system consists of a miniaturized fiberoptic probe which carries light signals into the esophagus and back to the optoelectronic system via a fiberoptic bundle. The Teflon probe head has a $2.0-\mathrm{mm}$ open groove across which emits two different wavelengths of light for material sampling. Two light-emitting diodes (at 470 and $565 \mathrm{~nm}$ ) represent the source for the measurement of bilirubin, the most common pigment in bile, and the reference signal (no bilirubin absorption), respectively. The portable photodiode system converts the light into an electrical signal. After amplification, the signals are processed by an integrated microcomputer, which calculates the differences of the absorbencies at 470 and $565 \mathrm{~nm}$. This value is directly proportional to the bilirubin concentration in the sample under study. The period between two successive pulses from the same source (sampling time) is $8 \mathrm{~s}$. In addition, the software averages the absorbencies calculated over two successive samplings in order to decrease the noise of the measurements.

Because Bilitec can monitor the presence of bilirubin, it has been suggested that this compound can serve as a surrogate marker for bile reflux. However, other authors were more cautious and preferred the term duodenogastroesophageal reflux (DGER) to denote that the technique is not specific for bile but rather for pancreatic and biliary output (pancreatic secretions and enzymes, bile acids, etc.).

The technique has been in use for more than 15 years but has never found a clear clinical role. Some authors have suggested using it in patients with history of gastric resection who report volume reflux-related symptoms (regurgitation, sour or bitter taste in the mouth). A more recent study suggested that the technique might be helpful in identifying DGER as the potential underlying cause for PPI failure [23]. The latter study boosted the popularity of the technique, which is currently used as one of the tools that assesses patients who continue to be symptomatic on PPI therapy.

\section{The Value of Bilitec}

By using Bilitec, several studies demonstrated a close correlation between Bilitec readings and bile acid concentration measurements of gastric aspirates. However, other studies have reported that bile reflux is a very uncom- 


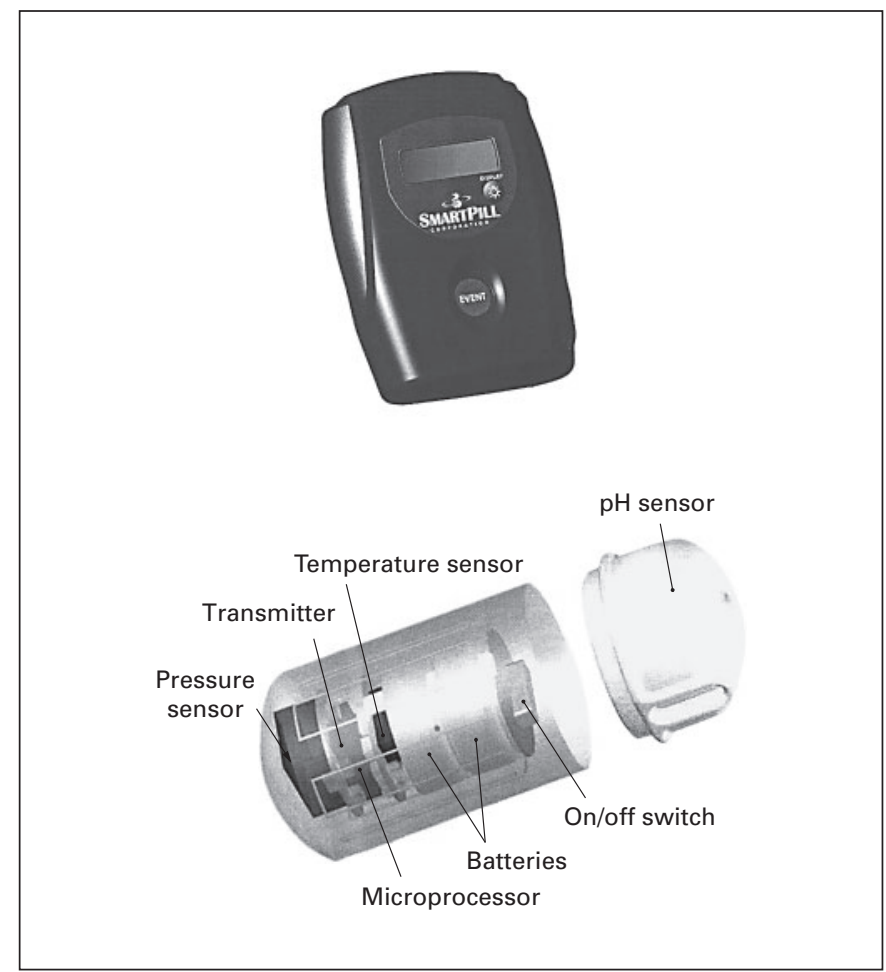

Fig. 2. SmartPill monitoring system (capsule and receiver).

mon cause of classic GERD-related symptoms. Marshall et al. [24] used Bilitec in symptomatic GERD patients and found that only the minority of symptoms (6\%) correlated with bile reflux into the esophagus.

Tack et al. [23] found that the addition of Bilitec to $\mathrm{pH}$ monitoring was better than $\mathrm{pH}$ monitoring alone in demonstrating the presence of ongoing reflux in GERD patients who failed PPI therapy. Esophageal acid exposure on PPI (once or twice a day) was abnormal in only $37 \%$ of the patients as detected by $\mathrm{pH}$ testing. However, by adding Bilitec measurements of DGER, the yield of the two procedures combined increased to $75 \%$. In another study that also used the combination of Bilitec and $\mathrm{pH}$ testing, the authors demonstrated a close correlation between the extent of combined acid and DGER and severity of esophageal mucosal involvement [25]. The combined reflux was documented in only $50 \%$ of NERD patients as compared with $79 \%$ of those with erosive esophagitis and 95\% of those with Barrett's esophagus. Furthermore, Vaezi and Richter [26] evaluated the role of acid and DGER in causing mucosal injury in patients post-partial gastrectomy and found that all patients with erosive esophagitis predominately demonstrated a mixed reflux pattern (acid and DGER). Additionally, DGER without simultaneous acid reflux resulted in symptoms, but was not associated with the presence of erosive esophagitis in this group of patients. Champion et al. [27] demonstrated in GERD patients who were treated with PPI a marked reduction not only in acid reflux but also in DGER. This is primarily because PPI therapy decreased the volume of gastric secretions.

In summary, Bilitec monitoring is a doable technique that assesses DGER. Its clinical role has evolved over the years and currently there is renewed interest in its potential use to evaluate PPI failure patients.

\section{SmartPill ACT-1 Capsule}

The SmartPill is a single-use, ingestible, new diagnostic capsule $(22 \times 11.7 \mathrm{~mm})$ (fig. 2$)$. A circumferential pressure sensor and an antimony $\mathrm{pH}$ sensor are embedded within the capsule. The device uses radiofrequency to transmit $\mathrm{pH}$ and pressure data to a receiver worn by the patient around the waist for $8 \mathrm{~h}$. Data from clinical trials indicate that this device can measure gastric emptying rate, gastric and intestinal $\mathrm{pH}$ and intestinal transit time [28]. Assessment of esophageal acid exposure is not currently available with the SmartPill ACT-1 capsule. However, future usage of this technique to assess intraesophageal $\mathrm{pH}$ is currently under evaluation. Additionally, this novel device is pending an FDA approval. 


\section{References}

1 Dent J, Brun J, Fendrick AM, et al: An evidence-based appraisal of reflux disease management - The Genval Workshop Report. Gut 1999;44:S1-S16.

$\checkmark 2$ Kahrilas PJ, Quigley EM. Clinical esophageal pH recording: a technical review for practice guidelines development. Gastroenterology 1996;110:1982-1996.

>3 DeVault KR, Castell DO: Updated guidelines for the diagnosis and treatment of gastroesophageal reflux disease. The Practice Parameters Committee of the American College of Gastroenterology. Am J Gastroenterol 1999;94: 1434-1442.

-4 Richter JE: Extraesophageal presentations of gastroesophageal reflux disease: an overview. Am J Gastroenterol 2000;95:S1-S3.

5 Fass R, Mackel C, Sampliner RE: 24-hour pH monitoring in symptomatic patients without erosive esophagitis who did not respond to antireflux treatment. J Clin Gastroenterol 1994; 19:97-99.

-6 Fass R, Hell R, Sampliner RE, et al: Effect of ambulatory 24-hour esophageal $\mathrm{pH}$ monitoring on reflux-provoking activities. Dig Dis Sci 1999;44:2263-2269.

7 Fass R: Empirical trails in treatment of gastroesophageal reflux disease. Dig Dis 2000;18: 20-26.

$>8$ Wong WM, Bautista J, Dekel R, et al: Feasibility and tolerability of transnasal/peroral placement of the wireless $\mathrm{pH}$ capsule vs. traditional 24-hour oesophageal $\mathrm{pH}$ monitoring - a randomized trial. Aliment Pharmacol Ther 2005; 21:155-163.

$\checkmark 9$ Martinez SD, Malagon IB, Garewal HS, et al: Non-erosive reflux disease - acid reflux and symptom patterns. Aliment Pharmacol Ther 2003; 17:537-545.

10 Pandolfino JE, Schreiner MA, Lee TJ, et al: Comparison of the Bravo wireless and Digitrapper catheter-based $\mathrm{pH}$ monitoring systems for measuring esophageal acid exposure. Am J Gastroenterol 2005;100:1466-1476.
11 Pandolfino JE, Richter JE, Ours T, et al: Ambulatory esophageal $\mathrm{pH}$ monitoring using a wireless system. Am J Gastroenterol 2003;98: 740-749.

12 Ward EM, DeVault KR, Bouras EP, et al: Successful oesophageal $\mathrm{pH}$ monitoring with a catheter-free system. Aliment Pharmacol Ther 2004;19:449-454.

13 Pandolfino JE, Kahrilas PJ: Prolonged pH monitoring: Bravo capsule. Gastrointest Endosc Clin N Am 2005; 15:307-318.

14 Prakash C, Clouse RE: Value of extended recording time with wireless $\mathrm{pH}$ monitoring in evaluating gastroesophageal reflux disease. Clin Gastroenterol Hepatol 2005;3:329-334.

15 Pandolfino JE, Kahrilas PJ, Cisler J, et al: Esophageal $\mathrm{pH}$ monitoring using a catheterfree $\mathrm{pH}$-system (Bravo ${ }^{\mathrm{TM}} \mathrm{pH}$ system) (abstract). Gastroenterology 2002;122:A-19, \#152.

16 Park W, Vaezi MF: Esophageal impedance recording: clinical utility and limitations. Curr Gastroenterol Rep 2005; 7:182-189.

17 Sifrim D, Holloway R, Silny J, et al: Acid, nonacid, and gas reflux in patients with gastroesophageal reflux disease during ambulatory 24-hour $\mathrm{pH}$-impedance recordings. Gastroenterology 2001;120:1588-1598.

18 Vela M, Camacho-Lobato L, Srivivasan R, et al: Simultaneous intraesophageal impedance and $\mathrm{pH}$ measurement of acid and nonacid gastroesophageal reflux: effect of omeprazole. Gastroenterology 2001;120:1599-1606.

19 Sifrim D, Dupont L, Blondeau K, et al: Weakly acidic reflux in patients with chronic unexplained cough during 24-hour pressure, $\mathrm{pH}$, and impedance monitoring. Gut 2005;54:449454.
20 Shay S, Tutuian R, Sifrim D, et al: Twenty-four hour ambulatory simultaneous impedance and pH monitoring: a multicenter report of normal values from 60 healthy volunteers. Am J Gastroenterol 2004;99:1037-1043.

21 Shay SS, Vela M, Richter J. Multichannel intraluminal impedance detects reflux events during the vulnerable period after a swallow that are missed by $\mathrm{pH}$ probe and manometry (abstract). Gastroenterology 2002;122:T1120.

$\checkmark 22$ Sifrim D, Castell D, Dent J, et al: Gastro-oesophageal reflux monitoring: review and consensus report on detection and definitions of acid, non-acid, and gas reflux. Gut 2004;53: 1024-1031.

23 Tack J, Koek G, Demedts I, et al: Gastroesophageal reflux disease poorly responsive to singledose proton pump inhibitors in patients without Barrett's esophagus: acid reflux, bile reflux, or both? Am J Gastroenterol 2004;99:981988 .

-24 Marshall RE, Anggianash A, Owen WA, et al: The relationship between acid and bile reflux and symptoms in gastro-oesophageal reflux disease. Gut 1997;40:182-187.

25 Vaezi MF, Singh S, Richter JE: Role of acid and duodenogastric reflux in esophageal mucosal injury: a review of animal and human studies. Gastroenterology 1995;108:1897-1907.

26 Vaezi MF, Richter JE: Contribution of acid and duodenogastro-oesophageal reflux to oesophageal mucosal injury and symptoms in partial gastrectomy patients. Gut 1997;41: 297-302.

27 Champion G, Richter JE, Vaezi MF, et al: Duodenogastroesophageal reflux: relationship to $\mathrm{pH}$ and importance in Barrett's esophagus. Gastroenterology 1994;107:747-754.

28 Kuo B, Viazis N, Bahadur S, et al: Non-invasive simultaneous measurement of intra-luminal $\mathrm{pH}$ and pressure: assessment of gastric emptying and upper GI manometry in healthy subjects (abstract). Neurogastroenterol Motil 2004; 16:666, \#61. 